\title{
How do doctors deliver a diagnosis of dementia in memory clinics?
}

Jemima Dooley, Nick Bass and Rose McCabe

\section{Background}

Dementia diagnosis rates are increasing. Guidelines recommend that people with dementia should be told their diagnosis clearly and honestly to facilitate future planning.

\section{Aims}

To analyse how doctors deliver a dementia diagnosis in practice.

\section{Method}

Conversation analysis was conducted on 81 video-recorded diagnosis feedback meetings with 20 doctors from nine UK memory clinics.

\section{Results}

All doctors named dementia; $59 \%(n=48)$ approached the diagnosis indirectly but delicately ('this is dementia') and $41 \%(n=33)$ approached this directly but bluntly ('you have Alzheimer's disease'). Direct approaches were used more often with people with lower cognitive test scores. Doctors emphasised that the dementia was mild and tended to downplay its progression, with some avoiding discussing prognosis altogether.

\section{Conclusions}

Doctors are naming dementia to patients. Direct approaches reflect attempts to ensure clear diagnosis. Downplaying and avoiding prognosis demonstrates concerns about preserving hope but may compromise understanding about and planning for the future.

\section{Declaration of interest}

None.

\section{Copyright and usage}

(c) The Royal College of Psychiatrists 2018.
Worldwide government initiatives are strongly advocating an increase in dementia diagnoses to be made at earlier stages of the condition. ${ }^{1,2}$ The National Institute for Health and Care Excellence (NICE) states 'People should be told their diagnosis as clearly and honestly as possible. Without this knowledge, people cannot begin to make sense of what is happening, nor can they plan effectively for their future'. ${ }^{3}$ The Memory Services National Accreditation Programme publish standards for memory clinics, but do not address the communication of the diagnosis other than 'the outcome of the assessment is communicated to all relevant parties in a timely manner'.

Previous studies have demonstrated that dementia presents a special set of considerations in breaking diagnostic news. ${ }^{5}$ Early symptoms are often noticed by family or friends who present to the doctor on the patient's behalf. ${ }^{6}$ People with dementia may not acknowledge the extent of their difficulties and resist going to the memory clinic. ${ }^{7}$ Most will have impaired short-term memory, attention and language processing and production. ${ }^{8}$ Currently in the UK, the clinician communicating the diagnosis will often be meeting the patient for the first time at diagnostic feedback and will have no preexisting relationship to guide the conversation. ${ }^{9}$ In the light of these complexities, the aim of this study was to microanalyse video recordings of diagnostic feedback consultations in memory clinics to describe how a diagnosis of dementia is communicated.

\section{Method}

\section{Data collection}

Data were video-recorded diagnostic feedback meetings collected through the National Institute for Health Research funded Shared Decision Making in Mild to Moderate Dementia (ShareD) study (PB-PG-1111-26063). Data collection took place in nine UKbased secondary care memory clinics in Devon (site A - a semirural and rural setting) and London (site B - an urban setting) from 2014 to 2015. The memory clinics followed the NICE pathway for dementia diagnosis, ${ }^{3}$ with specialist services performing brain scans, cognitive testing and patient histories before meeting as a multidisciplinary team. Doctors fed back the diagnosis to the patient and management was discussed. In site A, tests and feedback took place on the same day in a 'one-stop shop' clinic. In site B, the patient attended separate clinic visits for testing and diagnosis feedback.

All clinicians who delivered diagnoses in the participating memory clinics were approached. Consecutive sampling was used for patients. All patients attending the memory clinic for diagnosis feedback were eligible, except for patients needing interpreters because of the added complexity of the communication. Information sheets were sent with patient appointment letters, and researchers approached patients and their companions to obtain informed consent. Diagnostic feedback meetings were video recorded using Go Pro cameras. Camden and Islington Research Ethics Committee approved the study (13/LO/1309).

\section{Data analysis}

Data were analysed using conversation analysis. Conversation analysis is a method of microanalysing verbal and non-verbal communication to provide insight into what people say and how they say it. A transcription company transcribed the consultations verbatim. Sections related to the diagnosis were transcribed in detail for conversation analysis by the first author (57\%) and a conversation analysis transcription company $(43 \%) .{ }^{10}$ Visual features such as gaze and posture were also analysed. This enabled a description of the structure of the diagnosis feedback meeting, as well as a detailed description of the practices doctors use to deliver dementia diagnoses. Independent sample $t$-tests were used where relevant to identify whether the use of different communicative strategies was linked with patient cognitive test scores.

The inclusion of data from different doctors in a variety of clinics, as well as comparison with studies of diagnosis deliveries in other settings, enhanced reliability. ${ }^{11}$ Validity was addressed through repeated analysis within and beyond the research team. ${ }^{12}$ Findings were discussed with participating doctors. This did not 
change the results but aided the analysis by contextualising the communication practices within service structures and cultures. ${ }^{13}$

The conversation analysis transcripts presented have been simplified. The markers for prosody, stress and speed have been removed, leaving the markers for the overlapping speech (represented by square brackets) and length of silences (represented in seconds in brackets, with full stops representing pauses under $0.2 \mathrm{~s}$ ).

\section{Results}

\section{Participant characteristics}

The consent rate for clinicians participating in ShareD was $88 \%$. This data-set included 9 doctors from site A and 11 from site B (Table 1). There was a mean of four patients per doctor, ranging from one to nine. There were three doctors where only one patient was recruited. Of 423 patients approached, 216 took part (51\%). Of these, 101 patients were diagnosed with dementia, with the remaining patients being referred for further testing or receiving diagnoses of mild cognitive impairment, psychological conditions or not receiving a diagnosis. The first 81 consultations of dementia diagnosis feedback were analysed in this study as part of a $\mathrm{PhD}$ project. A total of 43 patients were from site A and 38 from site B. In $75 \%(n=61)$ of meetings doctors were meeting patients for the first time. Participant information is displayed in Table 2.

\section{Structure of the diagnostic feedback meeting}

Figure 1 displays the five core stages in the diagnostic feedback meetings, with the corresponding frequencies. Across the two sites there was less than $5 \%$ difference between these frequencies. In stages 1 and 2 doctors elicited patient orientation to the meeting and their perspective on their symptoms. In stage 3 the test results were fed back. The diagnosis was delivered in stage 4. In stage 5 treatment and management were addressed.

\section{Communication of the dementia diagnosis}

The communication of diagnostic information occurred in stages 1-4 with systematic practices occurring across the 81 meetings. There was no significant difference in how often these practices were used in site A and B. Additional examples of the practices described are available as supplementary material with the online publication of this article.

\begin{tabular}{|c|c|}
\hline Doctor characteristics & \\
\hline $\begin{array}{l}\text { Gender, } n(\%) \\
\text { Women } \\
\text { Men }\end{array}$ & $\begin{array}{l}11(55) \\
9(45) \\
\end{array}$ \\
\hline $\begin{array}{l}\text { Ethnicity, } n(\%) \\
\text { White British } \\
\text { White other } \\
\text { Asian or Asian British } \\
\text { Indian }\end{array}$ & $\begin{array}{l}13(65) \\
3(15) \\
2(10) \\
2(10)\end{array}$ \\
\hline $\begin{array}{l}\text { Clinician type, } n \text { (\%) } \\
\text { Consultant psychiatrist } \\
\text { Consultant geriatrician } \\
\text { Specialty doctor }\end{array}$ & $\begin{array}{l}15(75) \\
3(15) \\
2(10) \\
\end{array}$ \\
\hline $\begin{array}{l}\text { Clinic location, } n(\%) \\
\text { London } \\
\text { Devon }\end{array}$ & $\begin{array}{l}11(55) \\
9(45) \\
\end{array}$ \\
\hline Number of years working in dementia, mean (range) & $12(4-25)$ \\
\hline
\end{tabular}

Table 2 Patient and companion characteristics

Characteristic

Patient characteristics

Age, mean (range)

$80(52-92)$

Gender, $n$ (\%)

women

Men

$47(58)$

34 (42)

Ethnicity, $n$ (\%)

White British

White other

$61(75)$

Caribbean

$8(10)$

Asian other

3 (4)

Black or Black British

1 (1)

African

1 (1)

$1(1)$

Other

3 (4)

Missing

$3(4)$

Diagnosis, $n$ (\%)

Alzheimer's disease $\quad 47(58)$

Mixed dementia

$47(58)$

vascular dementia

$12(15)$

Dementia unspecified

Lewy body dementia

$3(4)$

Parkinson's dementia

2 (3)

semantic dementia

1 (1)

Cognitive test scores, mean (range)

Addenbrooke's Cognitive Examination-III $(n=67)$

Mini-Mental State Examination $(n=8) \quad 22(16-28)$

Missing $(n=6)$

Companion characteristics

At least one companion present, $n$ (\%) 75 (93)

Patients with two companions 6 (7)

Patients with three companions 2(2)

Gender, $n(\%)$

Women $53(64)$

Men 30 (36)

Relationship to patient, $n$ (\%)

$\begin{array}{ll}\text { Child/child in law } & 37(45) \\ \text { Spouse/partner } & 29(35)\end{array}$

Other $10(12)$

Friend $3(4)$

Sibling $3(4)$

Missing

1 (1)

Stage 1:

Eliciting orientation (83\% of meetings, $n=67$ )

Stage 2:

Eliciting perspective on symptoms $(85 \%, n=69)$

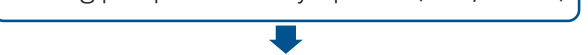

Stage 3:

Feeding back the test results $(79 \%, n=64)$

Stage 4:

Delivering the diagnosis $(100 \%, n=81)$

Stage 5:

Discussing treatment and support $(100 \%, n=81)$

Fig. 1 Stages of the diagnostic feedback meeting. 


\section{Stage 1: Eliciting orientation}

In the majority of meetings doctors elicited the patient's orientation to the purpose of the meeting, often explicitly asking about the patient's expectations (extract 1, line 1). If the patient (PT) did not display orientation, the doctor (DR) provided this information before proceeding (extract 1 , lines $4-10$ ).

\section{Extract 1}

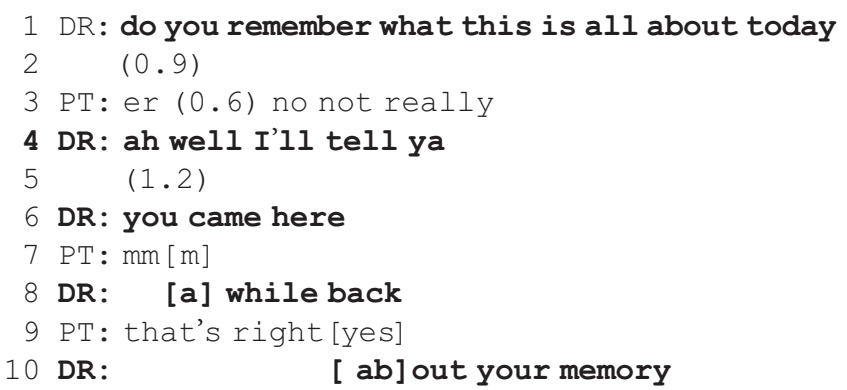

As in Extract 1, 62\% $(n=50)$ of patients demonstrated some uncertainty as to the purpose of the diagnosis feedback at this stage of the meeting. Although this could be attributed to short-term memory loss, in some cases it was evident other factors were involved. In extract 2, the patient does not respond after a significant pause (line 2) and her daughter (DAU) explains she had told the patient that the meeting was for the brain scan results. The patient had therefore not been informed of the possibility of a diagnosis (lines 3-4).

\section{Extract 2}

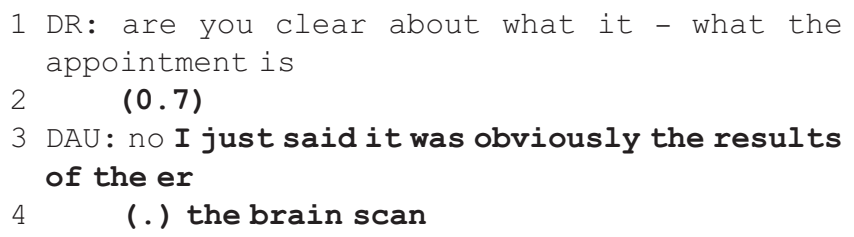

\section{Stage 2: Eliciting perspective to forecast the diagnosis}

Similar to other settings, doctors forecasted the diagnosis prior to delivery. Forecasting is a tool that allows recipients 'to estimate and predict what the news will be', and thus 'ultimately facilitates realisation'. ${ }^{14}$

Forecasting usually occurred in stage 2 of the meeting as doctors elicited the patient perspective on their symptoms, and then coimplicated their perspective in the diagnostic communication. In extract 3 , the doctor asks if the patient agrees that her memory is not 'as good as it used to be' (lines 1-2). The patient shows some disagreement (lines 3-8). In these cases, doctors did additional work to demonstrate the problem: the doctor here presents test results that contrast with the patient's view (lines 9-12). Doctors have been found to present evidence in this way to manage potential resistance and prepare patients for diagnosis. ${ }^{14,15}$

\section{Extract 3}

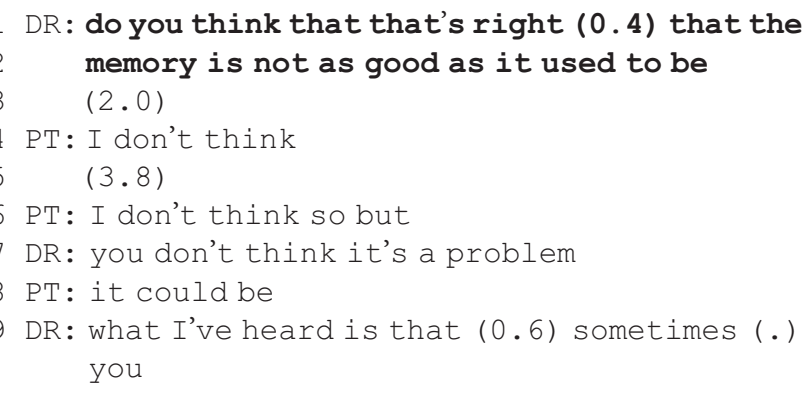

Conflict sometimes arose when doctors explored patient perspective while demonstrating prior knowledge of their situation. In extract 4 , the doctor's perspective elicitation includes symptom descriptions reported by the patient's daughter (lines 1-2, clarified in line 9 'family mentioned that'). The patient disagrees, indirectly questioning where the doctor got his knowledge ('I never said that', lines 4-8). When the doctor changes to an open question (lines 910) and the patient reports having good memory (line 12), the doctor takes a different tack asking if the patient has 'any problems' (line 14). The patient then describes a single recent incident (line 16), which, while still in conflict with the doctor and daughter's time frame of 9 months, the doctor can still use to build up to the diagnosis.

\section{Extract 4}

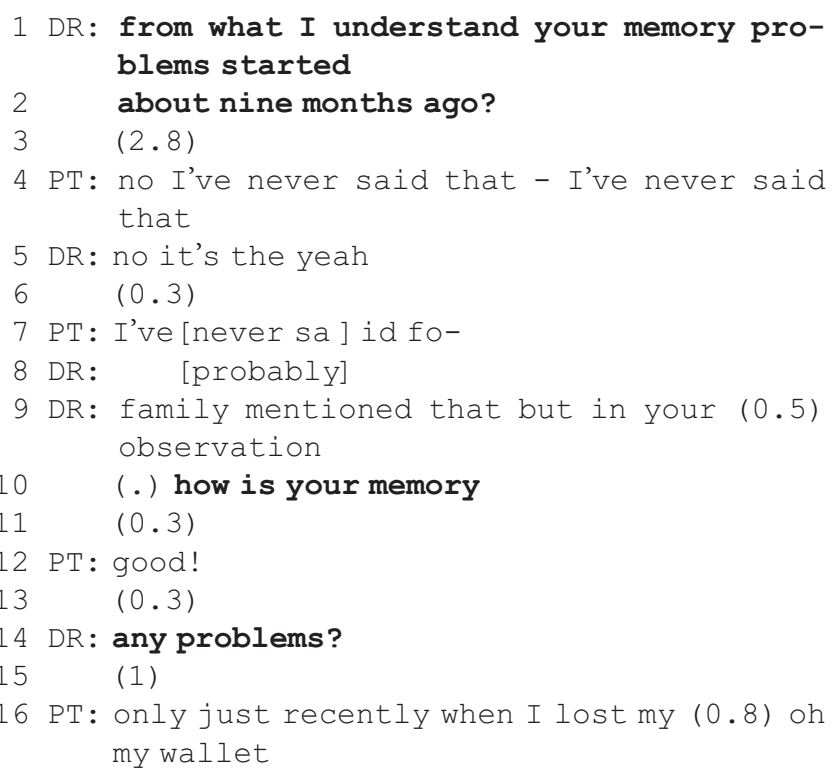

\section{Stage 3: Feeding back to the test results to forecast the diagnosis}

Doctors also forecasted the diagnosis as part of stage 3 in feeding back the test results: explicitly stating the patient has significant memory problems (extract 5, lines 1-2,4-5). This is an important part of the meeting as it may not be clear to patients which test provides the basis for the diagnosis. ${ }^{16}$

\section{Extract 5}

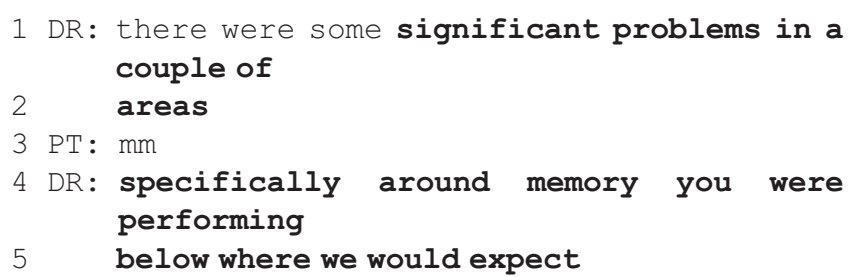

Stage 4: Delivering the diagnosis

All doctors named the dementia diagnosis in stage 4 of the meeting. The clear majority oriented their gaze and posture towards the patient on delivery, thus delivering the diagnosis to the patient and not their companion. 
In $25 \%(n=20)$ of meetings doctors asked patients if they wanted to know the diagnosis immediately before naming the diagnosis as dementia (extract 6, line 1).

\section{Extract 6}

1 DR: do you want to know what we'd call that memory

2 PT: yeah

3 DR: yeah so we - we'd call it a vascular dementia

None of the patients explicitly stated they did not want to know their diagnosis, and thus in all these cases the diagnosis was named.

Two diagnosis delivery formats were identified in the analysis: indirect and direct. The indirect, more delicate, format was more common (59\% of meetings, $n=48$; extract 7 , lines $1-3$ ). It involves presenting the symptoms or test results and labelling them as 'dementia'. This format requires some patient inference: they have these symptoms, and these symptoms are dementia, thus they have dementia. In other settings, it is a common way of delivering diagnoses in order to avoid strong emotional or resistant responses. ${ }^{17}$

\section{Extract 7}

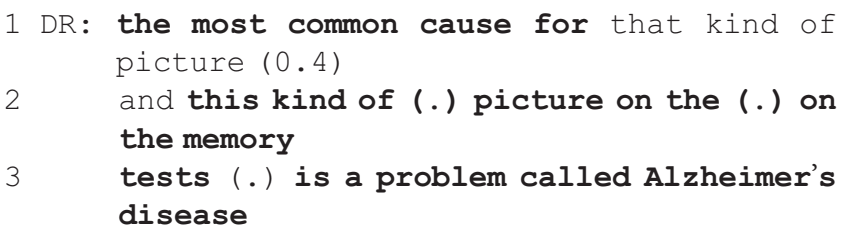

By contrast, the direct format $(41 \%, n=33)$ involved directly attributing the 'dementia' label to the patient, by using phrases such as 'you have' (extract 8, line 1). A direct format requires less patient inference to understand the diagnosis, but is interactionally more blunt and thus likely to increase emotional or resistant responses. $^{18}$

Extract 8

1 DR: we think that you have a dementia

Most doctors used different formats for different patients, with six doctors using the same format for all their patients (excluding the doctors where only one meeting was recorded, $n=3)$.

The relationship between the diagnosis format and patient scores on the Addenbrooke's Cognitive Examination (ACE)-III ${ }^{19}$ cognitive test was explored using an independent samples $t$-test. Too few patients were assessed on the Mini-Mental State Examination $^{20}$ to analyse these scores. ACE-III scores were lower among patients with whom doctors used a direct (mean score 64, s.d. $=13.32) v$. an indirect format (mean score 71 , s.d. $=13.31)(t$ $(63)=2.07, P=0.042)$.

Although the evidence for a diagnosis had been presented prior to naming dementia, doctors often re-referred to the evidence in the diagnostic utterance (55\%, $n=45$; extract 9, lines 1). Explicating the evidence makes the doctor's reasoning more visible and tends to be used in the face of potential resistance. ${ }^{15}$ This may also assist understanding among those with difficulty holding information in shortterm memory.

\section{Extract 9}

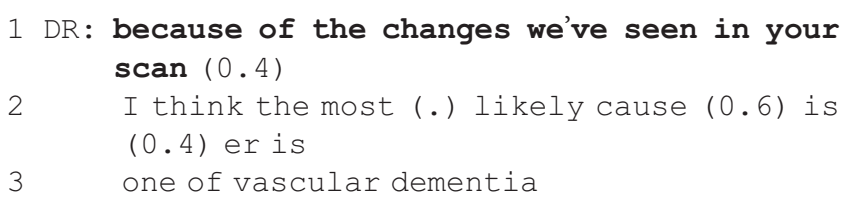

The diagnosis was often characterised as uncertain $(38 \%, n=$ 31) by doctors using phrases such as 'the most likely' or 'this probably is' (extract 10, line 1).

\section{Extract 10}

\section{DR: the most likely diagnosis that we can come up with is a \\ 2 mildAlzheimer's dementia}

An emphasis on dementia as a 'condition' or 'illness' was also common (49\%, $n=40$; Extract 11, line 1). Emphasising that dementia has a medical cause delineates symptoms from 'just old age', which is commonly how people explain dementia symptoms. ${ }^{21}$

\section{Extract 11}

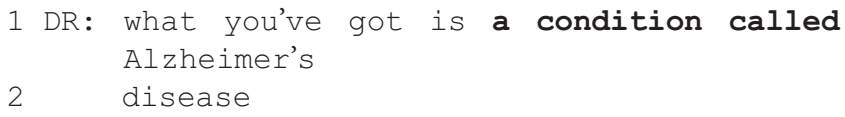

Doctors were seen to reassure patients that they had 'mild' dementia, including when patients scored well below the cut-off point on cognitive tests $(42 \%, n=34$; extract 12 , line 1$)$. This enabled doctors to frame the diagnosis positively, and differentiate the patient's situation from negative images of late-stage dementia.

\section{Extract 12}

1 DR: it's looking like an early form of a dementia 2 PT: yeah

\section{Stage 5: Delivering the diagnosis using good news exits}

Doctors used good news to exit the diagnosis discussion, emphasising the positive aspects of receiving treatment and support (53\%, $n=43$ ). This involved describing an 'optimistic projection' of the patient's future. ${ }^{22}$ In extract 13 , the doctor delivers the diagnosis and pursues a response by providing more information (lines 1-5). The patient passes up two opportunities to speak (lines 2, 5) and the doctor progresses to assess the diagnosis as 'good' because the patient will be able to start medication (lines 6-14).

\section{Extract 13}

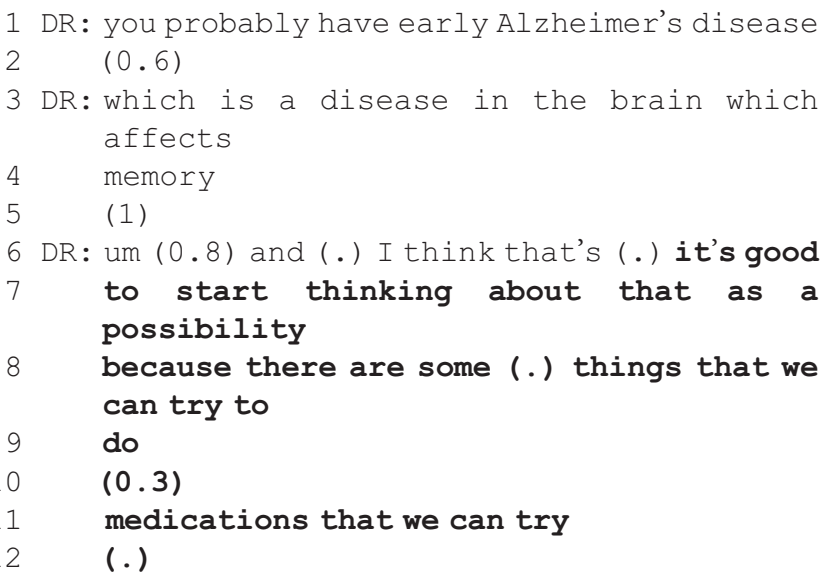



gression of

14 the memory problem

\section{Stage 6: Delivering the diagnosis - discussing prognosis}

Prognosis was explicitly discussed in $62 \%(n=50)$ of meetings and was approached sensitively with qualifications. In extract 14 , the doctor talks generically - 'generally speaking' (line 1) 'for most people we expect it to get a little worse' (lines 4-5) - rather than describing specifics. The deterioration is minimised, saying the dementia will get 'a little worse' (lines 4-5) over 'many years normally' (lines 7-8).

\section{Extract 14}

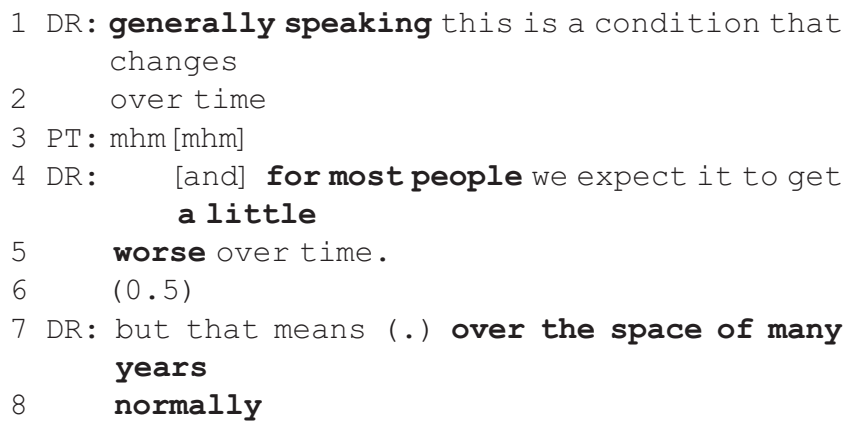

Prognosis was not discussed in $14 \%(n=11)$ of meetings. In $24 \%$ $(n=19)$ of meetings, prognosis was indirectly invoked when discussing the potential of medication to 'slow the progression of this memory problem' (extract 15, lines 3-4).

\section{Extract 15}

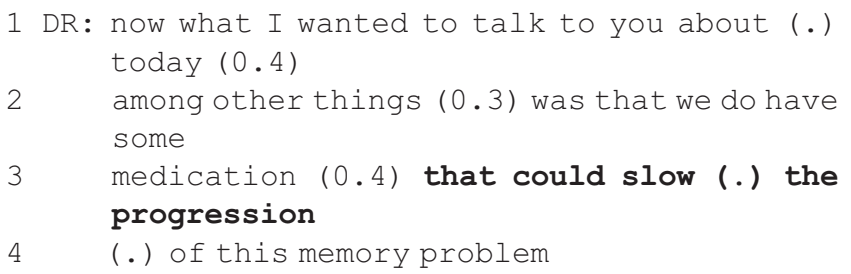

Medication was not offered to patients in $17 \%(n=14)$ of the meetings, because of their diagnosis not being eligible for treatment using cholinesterase inhibitors. Prognosis was discussed explicitly in $71 \%$ of these meetings $(n=10 / 14)$, a higher proportion of those where medication was discussed $(60 \%, n=40 / 67)$.

\section{Discussion}

\section{Main findings and comparison with previous studies}

All doctors in the study clearly named dementia. Doctors deployed specific strategies to make the diagnosis clear to patients, but often downplayed or avoided prognosis. Doctors elicited patient orientation to the purpose of the meeting. This has not been described in work examining the structure of primary care consultations, ${ }^{23}$ indicating that orientation is generally assumed in primary care but not in memory clinics. Over $60 \%$ of patients showed some uncertainty about the meeting purpose, which may be because patients have non-medical symptom explanations or companions are more proactive in seeking help. ${ }^{24}$ Additionally, as shown in extract 2, patients may not be informed as to the purpose of the diagnostic meeting. When patients do not expect a diagnosis, this can lead to more distress $^{25}$ and difficulty accepting the diagnosis and its consequences. ${ }^{26}$ Hence, eliciting orientation and forecasting the diagnosis prior to diagnosis delivery is important. However, guidelines advocate patient preferences for information should be ascertained prior to the diagnostic feedback meeting. ${ }^{27}$ Given that in $20 \%$ of meetings the doctors were asking if patients wanted to know the diagnosis immediately prior to delivery, this may not be happening in practice.

The common use of direct deliveries ('you have dementia') is different from cancer or HIV, where they are considered blunt and less sensitive. ${ }^{18,28}$ That direct deliveries occurred more often when patients had poorer cognitive functioning suggests doctors are overriding the normative, sensitive approach for a more blunt approach that may enhance understanding. Doctors also clarified the diagnosis by restating the evidence and differentiating the diagnosis from normal ageing. However, as the number of consultations is relatively small per doctor, it was not possible to analyse how doctors varied their approach with different patients. Additionally, previous work examining dementia diagnosis delivery has shown other aspects of communication, such as fractured sentences and hesitations, may negatively affect understanding, ${ }^{5}$ an aspect that was not explored in this study. Further work examining patient responses with a larger data-set, both before and after the consultation, would be necessary to draw conclusions on the effect these factors have on patient understanding and their emotional response.

That doctors are using strategies to enhance diagnostic understanding contrasts with previous research, which illustrates doctor avoidance of dementia diagnosis discussions. ${ }^{29,30}$ Although this may be because of the presence of video cameras, a study using video recordings by Peel also illustrated systematic avoidance of the 'dementia' label in data collected in 2012. ${ }^{30}$ This may therefore reflect a cultural shift, potentially because campaigns such as the National Dementia Strategy have emphasised the importance of receiving a diagnosis so people can plan and access support. These campaigns are having an effect on the perception of dementia among both the public and clinicians, ${ }^{31,32}$ which may be improving open diagnostic communication.

Indirect allusion to, avoidance of, and downplaying prognosis has been found previously in dementia ${ }^{5}$ and other settings ${ }^{33}$ where doctors often follow diagnostic news with positive discussions of treatment. ${ }^{34,35}$ Whereas this could be compounded by the fact not all people with dementia are eligible for medication, explicit discussions of prognosis occurred in slightly more meetings where medication was not offered. This indicates that a lack of treatment may not be the only reason that prognosis is avoided. Although how much people want to know about prognosis will vary, ${ }^{26}$ avoiding the subject means people may miss the chance to plan for their future. ${ }^{36}$ There have been initiatives to engage people in advance care planning at diagnosis, but doctors reflect that this is too early. ${ }^{37}$ However, given concerns that appropriate post-diagnostic support is not always available, if prognosis is not discussed at diagnosis people may have difficulty coping as the dementia progresses. ${ }^{38}$ More work is needed on how and when prognosis should be discussed.

Patients and companions will have a variety of explanations for dementia symptoms, from biological descriptions about brain changes, to social factors such as living alone, to psychological factors such as stress. ${ }^{7,39}$ These may affect how doctors communicate and also how patients and companions respond and adjust to the diagnosis. ${ }^{39,40}$ Although the diagnosis in this study was primarily delivered to patients (as judged by gaze on delivery), research has shown that companions become increasingly involved in treatment and support discussions. ${ }^{41}$ This study did not analyse the role of the companion in detail. However, where patient and companion expectations differ, there is potential for more difficult communication, for example in extract 2 the daughter had withheld the purpose of the meeting from her mother, and in extract 3 the daughter had given the doctor information that the patient did not agree with. 
These pre-existing relationship dynamics are an additional challenge for doctors when communicating the diagnosis. ${ }^{29}$

\section{Dementia diagnosis as a process}

Although this study reports a microanalysis of diagnosis delivery, it reflects wider discussions about what people want from a dementia diagnosis. Patients and companions prefer honesty but want to maintain hope. ${ }^{42}$ Providing this balance is a complex task, combining practical and moral dilemmas. ${ }^{43}$ Preferences for how, when and what information should be shared vary greatly. In general, doctors receive little training in diagnosis delivery beyond basic breaking bad news training, with most not receiving training specifically in psychiatry or dementia. ${ }^{9}$ Doctors report wanting to communicate information that is tailored to the individual, but find this difficult when meeting the patient for the first time, which applied to $75 \%$ of meetings. ${ }^{9}$ Additionally, provision of support and advice as the illness progresses is also extremely important. ${ }^{27}$ Conceptualising assessment and communication of a dementia diagnosis as a process, rather than a single event, is therefore integral.

\section{Strengths and limitations}

The strengths of this study come from a rigorous qualitative analysis of a large data-set, with a variety of different doctors, in specialist memory clinics in two different geographical areas. However, the sample did not extend to primary care or other settings where a diagnosis may be delivered. Additionally, all the clinicians in the study were medical doctors, and different healthcare professionals may approach the diagnosis differently. The consent rate was $51 \%$ and the $49 \%$ who declined may differ from those who participated, which may affect generalisability. Not all types of dementia or different ethnic and cultural groups were represented. The presence of cameras may have altered doctor communication. Finally, it was beyond the scope of this paper to analyse how patients responded to the diagnosis, or the role of the companions.

\section{Future directions for research}

In conclusion, doctors are clearly naming dementia but are more variable in discussing prognosis. Further work is needed to explore the ethical issues involved in communicating the degenerative nature of dementia in the diagnostic feedback meeting, as well as what information at this stage will facilitate planning for the future while also preserving hope.

Jemima Dooley, PhD, Population Health Sciences, University of Bristol, Bristol, UK; Nick Bass, MD MRCPsych, Division of Psychiatry, University College London, London, UK; Rose McCabe, PhD, University of Exeter Medical School, Exeter, UK

Correspondence: Jemima Dooley, 4.07, Canynge Hall, 39 Whatley Road, Bristol BS8 2PS, UK. Email: jemima.dooley@bristol.ac.uk

First received 17 May 2017, final revision 13 Oct 2017, accepted 1 Dec 2017

\section{Supplementary material}

Supplementary material is available online at https://doi.org/10. 1192/bjp.2017.64.

\section{Funding}

This paper presents independent research funded by the National Institute for Health Research (NIHR) under its Research for Patient Benefit (RfPB) Programme (Grant Reference Number PBPG-1111-26063), and supported by the NIHR Collaboration for Leadership in Applied Health Research and Care South West Peninsula. The views expressed are those of the authors and not necessarily those of the NHS, the NIHR or the Department of Health.

\section{Acknowledgements}

We thank all the patients, companions and healthcare professionals who allowed us to film the consultations, as well as Professor Gill Livingston and the ShareD project team.

\section{References}

1 Office of the Assistant Secretary for Planning and Evaluation. National Alzheimer's Project Act. ASPE, 2011 (https://aspe.hhs.gov/national-alzheimers-project-act).

2 Alzheimer Europe. National Dementia Strategies (Diagnosis, Treatment and Research). Alzheimer Europe, 2016. (http://www.alzheimer-europe.org/Policyin-Practice2/National-Dementia-Strategies).

3 National Institute for Health and Clinical Excellence. Dementia. National Institute for Clinical Excellence, 2006.

4 Hodge S, Hailey E, Colwill A, Walker L, Orrell M. Memory Services National Accreditation Programme (MSNAP). Memory Services National Accreditation Programme, 2016.

5 Karnieli-Miller O, Werner P, Aharon-Peretz, Eidelman S. Dilemmas in the (un) veiling of the diagnosis of Alzheimer's disease: walking an ethical and professional tight rope. Patient Educ Couns 2007; 67: 307-14.

6 Perry-Young L, Owen G, Kelly S, Owens C. How people come to recognise a problem and seek medical help for a person showing early signs of dementia: a systematic review and meta-ethnography. Dementia 2018; 17: 34-60.

7 Cahill SM, Gibb M, Bruce I, Headon M, Drury M. 'I was worried coming in because I don't really know why it was arranged': the subjective experience of new patients and their primary caregivers attending a memory clinic. Dementia 2008; 7: 175-89.

8 Karnieli-Miller O, Werner P, Aharon-Peretz J, Sinoff G, Eidelman S. Expectations, experiences, and tensions in the memory clinic: the process of diagnosis disclosure of dementia within a triad. Int Psychogeriatr 2012: 24: 1756-70.

9 Bailey C, Dooley J, McCabe R. 'How do they want to know?' Doctors' perspectives on making and communicating a diagnosis of dementia. Dementia (In press)

10 Jefferson G. Glossary of transcript symbols with an introduction. In Conversation Analysis: Studies from the First Generation (ed GH Lerner): 13-31. John Benjamins, 2004

11 Peräkylä A. Reliability and validity in research on naturally occurring social interaction. In Qualitative Research: Theory, Method, and Practice (ed D Silverman): 365-89. Sage, 2004.

12 Sidnell J, Stivers T. The Handbook of Conversation Analysis. Blackwell, 2013

13 Pomerantz A, Rintel ES. Practices for reporting and responding to test results during medical consultations: enacting the roles of 'paternalism' and 'independent expertise'. Discourse Stud 2004; 6: 9-26.

14 Maynard DW. Delivering bad news in emergency care medicine. Acute Med Surg 2016; 4: 3-11.

15 Peräkylä A. Agency and authority: extended responses to diagnostic statements in primary care encounters. Res Lang Soc Interact 2002; 35: 219-47.

16 Peräkylä A. Authority and accountability: the delivery of diagnosis in primary health care. Soc Psychol Q 1998; 61: 301-20.

17 Monzoni CM, Reuber M. Neurologists' approaches to making psychosocial attributions in patients with functional neurological symptoms. In Discourses of Helping Professions (eds E-M Graf, M Sator, T Spranz-Fogasy): 289-314. John Benjamins Publishing Company, 2014.

18 Maynard DW. On predicating a diagnosis as an attribute of a person. Discourse Stud 2004; 6: 53-76.

19 Mathuranath PS, Nestor PJ, Berrios GE, Rakowicz W, Hodges JR. A brief cognitive test battery to differentiate Alzheimer's disease and frontotemporal dementia. Neurology 2000; 55: 1613-20.

20 Folstein MF, Folstein SE, "Mini-mental state". A practical method for grading the cognitive state of patients for the clinician. J Psychiatr Res 1975; 12: 189-98.

21 Spanswick E. Three-quarters of Adults Believe Dementia is an Inevitable Part of Ageing. Care.home.co.uk, 2016 (https://www.carehome.co.uk/news/article. $\mathrm{cfm} / \mathrm{id} / 1574261 /$ british-adults-do-not-know-healthy-living-can-help-preventdementia).

22 Jefferson G. On 'trouble-premonitory' response to inquiry. Sociol Inq 1980; 50: 153-85.

23 Robinson JD. An interactional structure of medical activities during acute visits and its implications for patients' participation. Health Commun 2003; 15: 27-59.

24 Samsi K, Abley C, Campbell S, Keady J, Manthorpe J, Robinson L, et al. Negotiating a Labyrinth: experiences of assessment and diagnostic journey in cognitive impairment and dementia. Int J Geriatr Psychiatry 2014; 29: 58-67. 
25 Robinson L, Gemski A, Abley C, Bond J, Keady J, Campbell S, et al. The transition to dementia - individual and family experiences of receiving a diagnosis: a review. Int Psychogeriatr 2011; 23: 1026-43.

26 Bunn F, Sworn K, Brayne C, Iliffe S, Robinson L, Goodman C. Contextualizing the findings of a systematic review on patient and carer experiences of dementia diagnosis and treatment: a qualitative study. Health Expect 2015; 18: $740-53$

27 Guss R. Clinical Psychology in the Early Stage Dementia Pathway. British Psychological Society, 2014.

28 Gill VT, Maynard D. On 'labelling' in actual interaction: delivering and receiving diagnoses of developmental disabilities. Soc Probl 1995; 42: 11-37.

29 Dooley J, Bailey C, McCabe R. Communication in healthcare interactions in dementia: a systematic review of observational studies. Int Psychogeriatr 2015; 27: $1277-300$

30 Peel E. Diagnostic communication in the memory clinic: a conversation analytic perspective. Aging Ment Health 2015; 19: 1123-30.

31 Stites SD, Johnson R, Harkins K, Sankar P, Xie D, Karlawish J. Identifiable characteristics and potentially malleable beliefs predict stigmatizing attributions toward persons with Alzheimer's disease dementia: results of a survey of the U.S. General Public. Health Commun 2018; 33: 264-73.

32 Cheston R, Hancock J, White P. A cross-sectional investigation of public attitudes toward dementia in Bristol and South Gloucestershire using the approaches to dementia questionnaire. Int Psychogeriatr 2016; 28: 1717-24.

33 Leydon GM. 'Yours is potentially serious but most of these are cured': optimistic communication in UK outpatient oncology consultations. Psychooncology 2008; 17: 1081-8.

34 Maynard D. Shrouding bad news, exposing good news: the benign order of everyday life. In Bad News, Good News: Conversational Order in Everday Talk and Clinical Settings (ed D Maynard): 160-99. The University of Chicago Press, 2003.
35 Heritage J. Questioning in Medicine. In 'Why do you ask?': The Function of Questions in Institutional Discourse (eds AL Freed and S Ehrlich): 42-68. Oxford University Press, 2009

36 Detering KM, Hancock AD, Reade MC, Silvester W. The impact of advance care planning on end of life care in elderly patients: randomised controlled trial. BMJ 2010; 340: c1345

37 Brown J. Advance care planning in dementia. Lancet Psychiatry 2015; 2: 774-5.

38 Stokes L, Combes H, Stokes G. The dementia diagnosis: a literature review of information, understanding, and attributions. Psychogeriatrics 2015; 15: 21825.

39 Harman G, Clare L. Illness representations and lived experience in early-stage dementia. Qual Health Res 2006; 16: 484-502.

40 Sabat SR. The Experience of Alzhiemer's Disease: Life Through a Tangled Veil. Blackwell, 2001.

41 Karnieli-Miller O, Werner P, Neufeld-Kroszynski G, Eidelman S. Are you talking to me?! An exploration of the triadic physician-patient-companion communication within memory clinic encounters. Patient Educ Couns 2012; 88: 381-90.

42 Mastwyk M, Ames D, Ellis KA, Chiu E, Dow B. Disclosing a dementia diagnosis: what do patients and family consider important? Int Psychogeriatr 2014; 26: 1263-72.

43 Pinner G. Truth-telling and the diagnosis of dementia. Br J Psychiatry 2000; 176 : $514-5$ 